\title{
A 2010 Survey of the INACSL Membership about Simulation Use
}

\author{
Teresa Gore \\ Auburn University \\ Patrick Van Gele \\ University of Applied Sciences of Western Switzerland \\ Patricia K. Ravert \\ Brigham Young University - Provo, patricia-ravert@byu.edu \\ Cédric Mabire \\ University of Applied Sciences of Western Switzerland
}

Follow this and additional works at: https://scholarsarchive.byu.edu/facpub

Part of the Other Nursing Commons

\section{Original Publication Citation}

Gore, T., Van Gele, P., Ravert, P., \& Mabire, C. (2012, April). A 2010 Survey of the INACSL

Membership about Simulation Use. Clinical Simulation in Nursing. 8(4), e125-e133.

\section{BYU ScholarsArchive Citation}

Gore, Teresa; Van Gele, Patrick; Ravert, Patricia K.; and Mabire, Cédric, "A 2010 Survey of the INACSL Membership about Simulation Use" (2012). Faculty Publications. 5277.

https://scholarsarchive.byu.edu/facpub/5277

This Peer-Reviewed Article is brought to you for free and open access by BYU ScholarsArchive. It has been accepted for inclusion in Faculty Publications by an authorized administrator of BYU ScholarsArchive. For more information, please contact ellen_amatangelo@byu.edu. 


\title{
A 2010 Survey of the INACSL Membership about Simulation Use
}

\author{
Teresa Gore, DNP, FNP-BC ${ }^{a, *}$, Patrick Van Gele, MSN, RN ${ }^{b}$, \\ Patricia Ravert, PhD, RN, CNE, ANEF, FAAN ${ }^{c}$, Cédric Mabire, MSc, RN ${ }^{d}$ \\ ${ }^{a}$ Auburn University School of Nursing, Auburn, AL, USA \\ ${ }^{b}$ HECVSanté, University of Applied Sciences of Western Switzerland, Lausanne, Switzerland \\ ${ }^{c}$ Brigham Young University College of Nursing, Provo, UT, USA \\ ${ }^{d}$ School of Nursing, HECVSanté, University of Applied Sciences of Western Switzerland, Lausanne, Switzerland
}

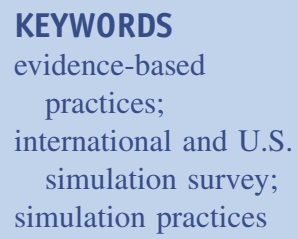

\begin{abstract}
Background: The survey was used to identify current nursing simulation practices of the INACSL membership.

Method: The similarities between U.S. and international responders identified: (a) the education/ experience of simulation educators, (b) use of a theory/conceptual framework, (c) use of commercial based simulation products and internally created scenarios, (d) interprofessional simulation, (e) student roles played in simulation, ( $f$ ) regulation of simulation by licensing/governing body, and $(\mathrm{g})$ simulations based on objectives.

Results: Significant differences were noted: (a) mandatory viewing of recording, (b) length of debriefing time, (c) ratio of simulation counted as clinical hours, (d) use of National League for Nursing simulation products, and (e) use of summative evaluation.

Conclusion: Study findings provide a global perspective and identify opportunities for research in nursing education.

\section{Cite this article:}

Gore, T., Van Gele, P., Ravert, P., \& Mabire, C. (2012, April). A 2010 survey of the INACSL membership about simulation use. Clinical Simulation in Nursing, 8(4), e125-e133. doi:10.1016/j.ecns.2012.01.002.

(C) 2012 International Nursing Association for Clinical Simulation and Learning. Published by Elsevier Inc. All rights reserved.
\end{abstract}

\section{Introduction}

High-fidelity manikins and standardized patients have been incorporated into nursing curricula for more than a decade, allowing participants to practice nursing care in a safe, controlled environment in order to promote clinical decision making and practice. Many curricula use a blend of simulation and traditional clinical hours with favorable

\footnotetext{
* Corresponding author: goreter@auburn.edu (T. Gore).
}

student outcomes; however, current literature is not clear regarding the correlation between simulation and improved clinical performance (National Council of State Boards of Nursing, 2011). With the increasing use and acceptance of simulation in nursing education, known evidence-based practices need to be incorporated into its use. Many aspects of simulation practice are supported in the literature: developing scenarios to meet specific learning objectives, planning scenarios so that they are appropriate to student level and learning, using a planned debriefing strategy, and 
employing a theoretical framework to plan and guide a simulation (Decker, Gore, \& Feken, 2011; Gaba, 2004; Howard, Englert, Kameg, \& Perozzi, 2011; Jeffries, 2007). There is a dearth of literature about incorporating best practices in simulation from an international perspective.

\section{Key Points}

- Findings provide a snapshot of simulation practices of INACSL members in 2010.

- Simulation practices in the international community and the U.S. demonstrates more similarities than differences.

- Development of simulation experiences should be grounded in a conceptual framework or theory. Education Technologies, Inc. $\left(\right.$ METI $\left.^{\mathrm{TM}}\right)$ human patient simulator $(N=116)$. Respondents included 34 schools of nursing and 6 simulation centers, for a response rate of $18.5 \%$. The international responses to this survey came from 1 school of nursing and 5 simulation centers. Nehring and Lashley found that simulation was still in the developmental phase, with simulation faculty learning to use the equipment and integrating simulation into the curriculum. Human patient simulation use in nursing education was in its infancy.

Nehring (2008) conducted a survey of boards of nursing in the United States, including the District of Columbia and Puerto Rico, on the use of high-fidelity simulation as a substitution for clinical time. In all, 44 responses were obtained, for a response rate of $88.5 \%$. Results revealed that five states and Puerto Rico had changed regulations to allow simulation to be counted as clinical time, with Florida as the only state that regulated the percentage. In addition, Nehring revealed that 16 states granted approval for simulation substitution while 17 states suggested regulations may change in the future.

More recently, the National Council of State Boards of Nursing (NCSBN) conducted a national survey of simulation use in nursing education (Hayden, 2010). All prelicensure registered nursing programs in the United States were asked to participate; the response rate was $62 \%$, with 1,060 surveys used in data analysis. Hayden found that simulation was used in $87 \%$ of responding programs, with $54 \%$ of these programs using simulation in at least five clinical courses. In all, $67 \%$ of the participants stated they had purchased commercially produced simulation scenarios; however, $78 \%$ had faculty members who wrote the scenarios. This survey revealed that $77 \%$ of responding programs substituted simulation for clinical time or would if permitted and that $69 \%$ of programs regularly or occasionally substituted simulation for clinical hours. The majority of clinical substitution with simulation occurred in medical-surgical nursing courses. Only 20\% of the respondents stated they would not substitute simulation for clinical time. The majority $(83 \%)$ stated simulation was substituted for clinical time at a 1:1 ratio; that is, 1 hour of simulation is equal to 1 hour of clinical time. These surveys revealed a widespread acceptance of simulation in the United States. No consolidated data were found on the use of simulation in Europe, the Middle East, Asia, or South America.

Previous studies have focused on the "big picture" of simulation and its incorporation into nursing curricula. With more simulation research and evidence being published, it is timely to review simulation practices worldwide to describe current practices, explore incorporation of best practices into simulation in nursing, and identify future study needs. We pondered whether there were differences between the applications of evidence-based practices for simulation in the United States and other countries. The research question for this study was, "Between the United States and other countries, what are the similarities and differences in simulation practices in nursing education?"

\section{Method}

\section{Instrument}

Two authors from the United States and one author from Switzerland collaborated to develop a survey to identify current nursing simulation practices. Survey questions were based on Gaba's (2004) dimensions of simulation application (Table 1), personal experience, literature review, interviews with simulation experts, and attendance at simulation presentations on best practices. The survey was reviewed and revised for face validity by selected members of the 2010 board of directors of the International Nursing Association for Clinical Simulation and Learning (INACSL). The INACSL board was selected because of its leadership role in nursing simulation and its mission to "promote research and disseminate evidence-based practice standards for clinical simulation methodologies and learning environments" and to become "Nursing's portal to the world of clinical simulation pedagogy and learning environments" (International Nursing Association of Clinical Simulation and Learning, 2010).

The survey included questions about (a) use of a theory or conceptual framework for simulation, (b) starting point for simulation, (c) debriefing time and use of video along with playback for participants, (d) interdisciplinary or interprofessional collaboration in simulation, (e) simulation hours regulated or used as clinical time, (f) participants' 
evaluation or assessment, (g) use of commercial scenarios or producing own simulation scenarios, and (h) participants' roles during a scenario. Survey respondents were also asked (a) their title, (b) highest level of education, (c) programs using simulation, (d) length of time institution had participated in simulation beyond static manikins and task trainers, (e) region or geographic location, and (f) types of simulators used.

\section{Sample}

Institutional review board approval was obtained through a southeastern U.S. institution affiliated with one of the authors. The online survey was sent to members of INACSL via Listserv ${ }^{\text {TM }}$ and e-mail. The time frame chosen for survey completion was April 12 to May 1, 2010. Membership in INACSL was between 900 and 1,000 during the study period. The international membership in INACSL at that time was 182, with 99 of the international members listing Canada as their place of residence. Members were asked to limit responses to one survey per institution in order to avoid duplication. However, some members of INACSL also had institutional membership, resulting in duplicate memberships and limiting the number of members who could respond to the survey. Thus the number of eligible potential respondents was estimated to be 800 . The sample size target response rate based on INACSL membership during the survey was 260 , with 50 international site responses, for a 0.95 confidence level (Creative Research Systems, 2011; Polit \& Beck, 2008). On completion of the initial phase of the survey in May 2010, the international responses were less than 30 . Additional international recruiting was conducted, and survey links were provided to international members of INACSL and through collaboration with the international members. The survey remained active until August 1, 2010. The final sample size included 254 participants, representing 48 international and 206 U.S. respondents.

\section{Table 1 Gaba's 11 Dimensions of Simulation}

1. Purpose of the simulation activity

2. The participants in the simulation

3. The level of experience of the participants

4. The health care domain(s) involved in the simulation

5. The health care discipline involved in the simulation

6 . The type of knowledge, skill, attitudes (KSA) focus of the simulation

7. The chronological age focus of the simulation

8. The technology available and required for the simulation

9. The environment of simulation

10. The level of participant interactivity during the simulation 11. Facilitation and debriefing method to be used in simulation

Note. Adapted from Gaba, D. M. (2004).

\section{Analysis of Data}

To compare the two independent subgroups, a twoproportion $z$ test using the Wald method was applied (Gauvreau, 2006). This test assumes equal variances in the populations and allows a determination of whether the U.S. responses were statistically different from those of the international respondents, by analogy to the comparison of the proportions from two independent populations. The Agresti and Caffo (2000) method was also used, yielding the same $z$ value results.

A two-sample $t$ test was also used to look for a significant difference in means between the sample populations. For the two-proportion $z$ test and $t$ test, the confidence interval was $95 \%$. All data were analyzed with the Stata 11.2 (2009) statistical analysis software program.

\section{Results}

A total of 254 participants completed the survey as of August 2010. Of the responses, 206 were from the United States and 48 were international. The confidence interval was $94.2 \%$ for the 254 responses (Creative Research Systems, 2011). This indicated an increased likelihood that the survey represented actual simulation practices within the general population. Characteristics of the respondents, including international geographic regions, are provided in Table 2. The findings from the survey regarding similarities and differences are reported in Table 3.

The majority of respondents had a master of nursing qualification and more than 3 years' experience with simulation. Although respondents had advanced degrees and experience, only $44 \%$ of the U.S. and $52 \%$ of the international community identified using a conceptual framework or theory. Most of the respondents reported combining commercial-based simulation products and internally created scenarios. The majority of respondents reported their simulation scenarios were based on the objectives and the level of experience of the participants.

Debriefing practices of the respondents revealed that the majority of respondents video recorded simulations. The international group used this practice more often than did the U.S. respondents $(p=.05)$. The international respondents also incorporated mandatory viewing of these video recordings by students more than the U.S. group did ( $p=$ .001). There were differences in the length of debriefings. The U.S. respondents most often implemented debriefing time equal to simulation time, while the international respondents most often implemented debriefing time twice as long as the simulation $(p=.01)$.

\section{Discussion}

The purpose of this study was to identify the similarities and differences in nursing education simulation practices 
Table 2 Characteristics of Respondents

\begin{tabular}{|c|c|c|c|c|}
\hline Responses of Participants & $\begin{array}{l}\text { International Sites }(N=48) \\
N(\%)\end{array}$ & $\begin{array}{l}\text { United States }(N=206) \\
N(\%)\end{array}$ & z Value & $p$ Value \\
\hline Undergraduate degree & $11(23)$ & $26(13)$ & 1.75 & .08 \\
\hline Master's degree & $31(65)$ & $136(66)$ & -0.13 & .89 \\
\hline Nursing & $18(58)$ & $132(97)$ & $-6.46^{*}$ & $.001^{*}$ \\
\hline Other & $13(42)$ & $4(3)$ & $6.46^{*}$ & $.001^{*}$ \\
\hline Doctoral degree & $6(12)$ & $44(21)$ & -1.42 & .15 \\
\hline $\mathrm{PhD}$ & $6(100)$ & $20(45)$ & $2.39^{*}$ & $.017^{*}$ \\
\hline EdD & & $8(18)$ & & \\
\hline DNP & & $9(21)$ & & \\
\hline Other doctorate & & $7(16)$ & & \\
\hline \multicolumn{5}{|l|}{ International regions } \\
\hline Asia Pacific & $2(4)$ & & & \\
\hline Atlantic islands & $1(2)$ & & & \\
\hline Canada & $30(63)$ & & & \\
\hline Europe & 9 (19) & & & \\
\hline Middle East & $4(8)$ & & & \\
\hline Other & $2(4)$ & & & \\
\hline \multirow[t]{2}{*}{ Years of experience beyond task trainers } & M & M & $t$ Value & $p$ Value \\
\hline & 3.61 & 3. 77 & 0.41 & .65 \\
\hline
\end{tabular}

between the United States and other countries. This information helps to provide a global perspective on the use of simulation and identifies opportunities in nursing education and further research.

Many findings revealed similar practices in the United States and at international sites, including (a) interdisciplinary simulation, (b) simulation hour regulation, (c) students playing roles as members of other disciplines, (d) ways in which the topic and content of simulation scenarios were determined, (e) use of formative and skillscheck method of evaluation, (f) use of some commercial simulation scenarios, and (g) the time participants' institutions have used simulation. The survey also revealed some differences between the international and U.S. nursing simulation communities, including (a) length of debriefing, (b) video capture and mandatory viewing of simulation, (c) use of summative evaluation or assessment, (d) simulation substituting for clinical hours, (e) ratio of use of simulation as clinical hours, and (f) use of purchased National League for Nursing (NLN) simulation scenario products.

\section{Use of a Conceptual Framework or Theory in Simulation Practices}

Although the percentage of programs using a theory or conceptual framework in simulation was similar, the number was very low among all respondents. The use of a conceptual framework or theory was reported in less than $50 \%$ of responses, even though the respondents had a graduate degree and years of experience. Because most nurse educators search for best practices and effective teaching strategies, this finding was surprising. An application of theory and/or conceptual frameworks to the teaching strategy of simulation would be beneficial. We believe it is possible that educators were actually using a theory or conceptual framework; however, it was not formally named or recognized.

\section{Interdisciplinary or Interprofessional Simulation and Role-Playing}

Similarities were revealed in interprofessional simulation. Only about half the respondents provided interprofessional simulation experiences. This finding was not unexpected given that the majority of nursing education occurs in nursing schools, not health science centers, where interprofessional education occurs in the same building. There is a growing call for interdisciplinary or interprofessional education worldwide. Frenk et al. (2010) stated health care delivery and education are fragmented and lacking in teamwork, leading to suboptimally prepared graduates. Through simulation, all health care professionals could learn to collaborate and work, as members of a team, for better patient outcomes. Some rationale for the low rate of interdisciplinary simulations are (a) the workplace and education system structure, (b) geographic separation on different campuses, (c) the tendency to practice and teach in silos, (d) turf protection, (e) lack of mutual respect, and (f) lack of funding and administrative support (Angelini, 2011). Many programs that conduct interprofessional simulation experiences do so only occasionally. The institutions that incorporate more interprofessional simulation tended to be health science centers or simulation 
centers with multiple disciplines using the same laboratory space and equipment. The logistics of scheduling the lab with multiple disciplines can present obstacles (Alinier, 2007; Angelini, 2011; Leonard, Shuhaibar, \& Chen, 2010; Reese, Jeffries, \& Engum, 2010).

If students are not participating in interprofessional simulation, are they learning the roles and responsibilities of other health care team members for collaboration purposes in patient care? The practice of allowing students to participate in simulation in roles other than the nurse, including roles as members of other disciplines, was similar across respondent categories. By allowing the students to practice as the nurse, role-playing occurs, and the students practice techniques in a safe, controlled environment. Some programs allow students to role-play members of other disciplines. This practice remains controversial when students are trying to socialize into their own profession. A student role-playing a member of another discipline may not have the knowledge to accurately portray the other discipline. Inaccurate role-playing may lead to jousting between disciplines and to poor collaboration and communication.

The proponents of role-playing members of other disciplines believe the student can learn the general function, responsibilities, and duties of other professions. Doing so may assist the student in learning the scope of other roles and in delegating. These points of view and practice were obtained by the authors attending simulation conferences, the INACSL Listserv ${ }^{\mathrm{TM}}$ communications, and discussion with simulation leaders. However, there is a lack of literature to support this practice, and it warrants further investigation.

\section{Starting Point for Simulation Scenario Development and Use}

We queried respondents concerning how the topic and content of simulation scenarios were determined. Current evidence suggests that simulated clinical experience should focus on course, clinical, or program objectives and be based on the participants' level of experience (International Nursing Association of Clinical Simulation and Learning Board of Directors, 2011). Many institutions determined the scenarios for a simulated clinical experience by reviewing and selecting from commercially purchased simulation scenarios (NLN scenarios, METI Program for Nursing Curriculum Integration [PNCI], Elsevier simulation products, and Pearson products). While reviewing the data collected regarding the use of purchased simulation scenario products, we noted that most respondents purchased and used more than one product (Table 3). Along with the purchased scenarios, the majority of participants produced their own scenarios within their institution, supporting the NCSBN survey findings (Hayden, 2010).

While reviewing the data collected regarding the use of purchased simulation scenario products, we noted most
U.S. respondents purchased and used more than one product. However, the NLN product tends to be used significantly more in the United States. We speculate that because the NLN is one of two large U.S. nursing education accrediting organizations and has developed a partnership with Laerdal ${ }^{\mathrm{TM}}$ to study and promote effective use of simulation, the NLN scenario product is readily available and widely promoted in the United States (Jeffries, 2007). Another possible explanation of its lower use in international sites may be the scenarios are United States-centric and may not align with other countries' practices or culturally appropriate care. The international simulation community may also perceive that the NLN scenarios were developed by an accrediting agency for U.S. nurses and may not be applicable in their own setting. Last but not least, there is limited literature available on simulation best practices in languages other than English.

\section{Debriefing Practices}

Respondents were asked about debriefing length and the video recording of simulation experiences and whether video-recorded viewing was used. Debriefing practices of the respondents revealed both similarities and differences (Table 3). An important aspect of a successful simulation experience is to designate a specific time for the debriefing process, allowing the students the opportunity to reflect and further clarify concepts from the simulation experience. Many experts report that the debriefing session is the most important components of a simulated learning experience and that much learning occurs as concepts are clarified (Childs \& Sepples, 2006; International Nursing Association of Clinical Simulation and Learning Board of Directors, 2011; Waxman, 2010). The time for debriefing was noted as a difference between the groups. In the United States, debriefing time is most often equal to simulation time, whereas among international respondents, debriefings are most often twice as long as simulations. This is a significant finding since many educators believe the best practice is debriefings that are at least as long as simulated clinical experiences; however, further investigation is warranted (Arafeh, Hansen, \& Nichols, 2010; Chronister \& Brown, in press; Neill \& Wotton, 2011; Salas et al., 2008; Waxman, 2010; Wotton, Davis, Button, \& Kelton, 2010).

Results showed significant differences between the United States and international sites regarding the use of video recording of simulations. International sites reported higher use of video recording during the simulation, as well as mandatory student viewing of the recording. Use of video playback has demonstrated value in simulation debriefing because it allows the simulation participants to see their actions and/or inactions in real time rather than relying on recall (Decker et al., 2011; Johnson-Russell \& Bailey, 2010). Although the majority of respondents reported that simulations are captured on video, most 
Table 3 Comparison of Practices between International and U.S. Sites

\begin{tabular}{|c|c|c|c|c|}
\hline Question & $\begin{array}{l}\text { International } \\
(N=48) \\
N(\%)\end{array}$ & $\begin{array}{l}\text { United States } \\
(N=206) \\
N(\%)\end{array}$ & $z$ Value & $p$ Value \\
\hline \multicolumn{5}{|l|}{$\begin{array}{l}\text { 1. A. Do you have students from other disciplines or } \\
\text { interdisciplinary professionals participate } \\
\text { in simulations with students? }\end{array}$} \\
\hline Yes & $23(48)$ & $86(42)$ & 0.75 & .45 \\
\hline \multicolumn{5}{|l|}{ B. If so, how often? } \\
\hline Always & 0 & $2(2)$ & 0.99 & .32 \\
\hline Often & $9(39)$ & $31(36)$ & 0.39 & .70 \\
\hline Seldom & $14(61)$ & $53(62)$ & 0.13 & .90 \\
\hline \multicolumn{5}{|l|}{$\begin{array}{l}\text { 2. Do you allow students to perform in roles } \\
\text { other than those training for? }\end{array}$} \\
\hline Yes & $33(69)$ & $165(80)$ & 1.62 & .10 \\
\hline 3. Use of theory or conceptual framework & $25(52)$ & $90(44)$ & 1.05 & .29 \\
\hline \multicolumn{5}{|l|}{$\begin{array}{l}\text { 5. Are simulation hours counted as clinical hours? } \\
\text { If yes, what is the ratio? }\end{array}$} \\
\hline Not Counted & $27(56)$ & $36(17)$ & $5.67^{*}$ & $.001^{*}$ \\
\hline $1: 1$ & $18(38)$ & $119(58)$ & $2.50^{*}$ & $.01^{*}$ \\
\hline $1: 2$ & 0 & $18(9)$ & $2.16^{*}$ & $.03^{*}$ \\
\hline $1: 3$ & 0 & $17(8)$ & $2.03^{*}$ & $.04^{*}$ \\
\hline Other & $3(6)$ & $16(8)$ & 0.67 & .50 \\
\hline \multicolumn{5}{|l|}{$\begin{array}{l}\text { 6. Use purchased simulation scenario products with } \\
\text { high-fidelity simulations (choose all that apply) }\end{array}$} \\
\hline NLN & $8(17)$ & $125(61)$ & $5.50^{*}$ & $.001^{*}$ \\
\hline METI/PNCI & $16(33)$ & $48(23)$ & 1.52 & .13 \\
\hline Produce own scenarios & $33(69)$ & $119(58)$ & 1.46 & .14 \\
\hline Pearson & 0 & $3(1)$ & 0.68 & .49 \\
\hline Other & $2(4)$ & $10(5)$ & 0.33 & .73 \\
\hline \multicolumn{5}{|l|}{ 7. What is the starting point for simulation? } \\
\hline Based on objectives \& student level & $45(94)$ & $171(83)$ & 1.87 & .06 \\
\hline Based on faculty or instructor request & $3(6)$ & $33(16)$ & 1.80 & .07 \\
\hline Other & 0 & $2(1)$ & & \\
\hline \multicolumn{5}{|l|}{ 8. A. Do you video record simulation? } \\
\hline Yes & $37(77)$ & $134(65)$ & $1.96^{*}$ & $.05^{*}$ \\
\hline \multicolumn{5}{|l|}{ B. If so, is it mandatory for student to view? $(N=37)$} \\
\hline Yes & $11(30)$ & $26(19)$ & 1.68 & .09 \\
\hline \multicolumn{5}{|l|}{ 9. How long is debriefing? } \\
\hline Half as long as simulation & $11(23)$ & $27(13)$ & 1.78 & .07 \\
\hline Equal to simulation & $9(19)$ & $84(41)$ & $2.92^{*}$ & $.01^{*}$ \\
\hline Twice as long as simulation & $21(44)$ & $74(36)$ & 1.07 & .28 \\
\hline Other & $7(14)$ & $21(10)$ & 0.84 & .40 \\
\hline \multicolumn{5}{|l|}{ 10. What is your method of assessment or evaluation? } \\
\hline Formative assessment & $24(50)$ & $82(40)$ & 1.29 & .19 \\
\hline Summative evaluation & $11(23)$ & $80(39)$ & $2.12^{*}$ & $.03^{*}$ \\
\hline Skills checklist & $10(21)$ & $37(18)$ & 0.54 & .58 \\
\hline No answer & $3(6)$ & $7(3)$ & 1.01 & .31 \\
\hline
\end{tabular}

Note. METI = Medical Education Technologies, Inc.; NLN = National League for Nursing; PNCI = METI's Program for Nursing Curriculum Integration.

${ }^{*} p$ value $<.05$ and $z$ value at 0.05 critical level is $<-1.96$ to $>+1.96$ (Adapted from Gravetter \& Wallnau, 2004).

U.S. respondents reported that students are not required to view the recordings. This is a seeming incongruity. It may be that many institutions have installed the recording equipment but may not be familiar with using it to facilitate a video-assisted debriefing. Another possible explanation is that once the simulation scenario is completed, the facilitator begins the debriefing process and does not want to use the video, which may add time to the debriefing. We speculate that as simulation use increases, less time may be available to review the video recordings or locate pertinent video clips for debriefing. Time constraints may outweigh the benefits of viewing the video. As a possible 
solution, a facilitator could allow participants to view their performance at a different time. However, with the increase in technology, faculty must also be aware of the potential loss of confidentiality. Once students have access to the video, there is a chance that a simulated clinical experience could be posted on social medias such as YouTube $^{\mathrm{TM}}$ and Facebook ${ }^{\mathrm{TM}}$. Confidentiality and privacy issues must be addressed to prevent violation of the safe environment of simulation and the participants' rights to privacy.

\section{Method of Assessing, Evaluating Student Performance in Simulation}

Along with debriefing, evaluation or assessment of simulation participant performance is an important aspect of an effective learning experience. Respondents were asked about their method of assessing or evaluating student performance in simulation. The evaluation and/or assessment of the participants should depend on the focus and desired outcome of the simulation experience. Students should know how they will be evaluated or assessed prior to the simulation (Decker et al., 2011; Jeffries \& McNelis, 2010). Our survey revealed a significant difference in the use of simulation for summative evaluation, with U.S. use higher. Reasons for more summative evaluation in the United States could be related to discussions about highstakes testing and a focus on evaluating student performance and outcomes related to simulation. The NLN is currently discussing the use of simulation for high-stakes testing. Objective structured clinical examinations are currently used by medical schools for high-stakes testing and simulation (Boulet, 2008; National League for Nursing, 2010); Canada applies the same strategy. In Europe, however, most countries do not have a regulatory board of nursing, and certification is delivered by accredited universities based on overall student academic performance and not on a final test similar to the National Council Licensure Examination in the United States (Robinson \& Griffiths, 2007). Evaluation instruments for student satisfaction, learning, and outcomes regarding simulation are seldom translated and validated in the international context (Simoneau, Van Gele, Ledoux, Lavoie, \& Paquette, 2011) may also be considered an obstacle to simulation development and evaluation.

\section{Simulation as Clinical Hours}

Although both U.S. and international sites report that simulation hours in nursing programs are regulated by some type of governing body, there are significant differences over counting simulation as clinical hours. In the United States, because of requirements imposed by the individual state boards of nursing, there are significant differences in the way states count simulation as clinical hours. Of the international simulation responses, $56 \%$ indicated that simulation was not counted as clinical hours, compared with $17 \%$ in the United States. Furthermore, the international sites that counted simulation as clinical hours reported that 1 hour of simulation is equal to 1 hour of clinical time (1:1), whereas U.S. responses indicated various ratios of simulation to clinical hours. Hayden (2010) found similar results to this question, in the U.S. with $69 \%$ of the institutions regularly substituting clinical hours and $77 \%$ suggesting they would substitute simulation for clinical hours if not regulated, compared to $75 \%$ of the respondents in this survey. In the United States, some state boards of nursing have determined a percentage of time that simulation can be used in place of clinical time; this varies from state to state (Nehring, 2008). In the U.S., the NCSBN is currently evaluating the substitution of simulation hours for clinical hours at rates of $25 \%$ and $50 \%$; presently, rates vary from state to state. This concept is also under review in the European countries.

Internationally, there is wide variation in approaches to regulating clinical training and laboratory use for nursing education, with the majority of countries having no regulation of simulated practice. In Europe, for example, nursing regulation and recognition of qualification is governed by European Economic Community (EEC) Directives 77/452/EEC and 77/453/EEC, which were implemented by EEC members in 1979. Every European country implements these directives according to its own laws and educational strategies. These directives and professional standards are very generic, vague, and nonprescriptive. When these directives were established, there were no recommendations for the use of simulation in nursing education. These directives have a requirement of 2,300 direct care hours for completion of a nursing program in Europe; however, there is no national standard for a set number of direct hours required for completion of a nursing program in the United States.

The United Kingdom is the only European country that has issued any recommendations for implementing simulation in the undergraduate nursing programs. The Nursing and Midwifery Council (2007) recommended that up to 300 hours of simulated and laboratory practice learning within the preregistration nursing curriculum may be used in support of the 2,300 direct care hours. More change that could influence the use and acceptance of simulation hours as clinical hours is the task of raising all nursing education to the bachelor's level by 2010, as agreed by all European countries (Bologna Communiqués, 1999; Sursock \& Smidt, 2010). With this reform, the EEC directives are now under revision. The revised directives are expected to include the use of simulation or virtual practice as part of clinical practice hours. (Zabalegui et al., 2006). In Eastern Europe, the Middle East, Asia, and South America, nurse educators have developed or implemented initiatives to incorporate simulation in the pregraduate nursing curriculum (Gonzalez, in press). 


\section{Limitations}

Several limitations were identified regarding this study. International participants' response rate was disproportionately low compared with the U.S. response rate, a difference that may be related to the limited international membership in INACSL. Another limitation is the high membership and response rate from Canada. The survey was sent in English only, potentially making it inaccessible to non-English speaking members. Even though the respondents were INACSL members, there may be other simulation educators whose views were not represented in this survey.

\section{Conclusion}

The use of simulation in nursing education is increasing worldwide. Based on the growing membership in simulation organizations and increasing publications about simulation, it is safe to say that global interest in nursing simulation is gaining momentum. Simulation practices in the international community and the U.S. demonstrate more similarities than differences. Inquiring about similarities and differences triggers new questions about simulation practice. Some of the potential questions that need to be answered to move the art and science of simulation forward are the following:

- Why is a conceptual framework for simulation used in only approximately $50 \%$ of simulation practice?

- What is the appropriate use of simulation as clinical experiences or hours? What is the best ratio for substituting simulation as clinical hours, 1:1, 1:2, 1:3, or a clinical day?

- How long should debriefings last, and what method of debriefing is most effective?

- If a simulation is video recorded, what is the best use of the recording? How should students view and respond to the video?

- What are the best methods of evaluation? What are best practices for formative assessment and summative evaluation?

- What are effective methods for incorporating more interdisciplinary/interprofessional simulation?

- How are standards for simulation being used (International Nursing Association of Clinical Simulation and Learning Board of Directors, 2011; Neill \& Wotten, 2011)?

Because of the rapid adoption of simulation and the changing environment of professional regulation, ongoing research is needed. Research should focus on the pedagogy of simulation as an educational strategy, the incorporation of simulation across the curriculum, the application of evidence-based practices, and the amount of simulation that produces the best outcomes. In the fall of 2011, the NCSBN (https://www.ncsbn.org/2094.htm) began a multisite, national, longitudinal study of simulation use in prelicensure nursing programs in the United States. A cohort of participating students will be followed in the clinical setting for 1 year postgraduation. This research will provide answers for some of these questions from a U.S. perspective and may provide material for reflection in other countries also. Continued research of simulation as an education strategy is warranted and will provide answers to these questions in order to encourage the appropriate use of the pedagogy.

\section{References}

Agresti, A., \& Caffo, B. (2000). Simple and effective confidence intervals for proportions and differences of proportions result from adding two successes and two failures. American Statistician, 54(4), 280-288.

Alinier, G. (2007). Enhancing trainees' learning experience through the opening of an advanced multiprofessional simulation training facility at the University of Hertfordshire. British Journal of Anaesthetic and Recovery Nursing, 8(2), 22-27.

Angelini, D. J. (2011). Interdisciplinary and interprofessional education: What are the key issues and considerations for the future? Journal of Perinatology \& Neonatology, 25(2), 175-179.

Arafeh, J., Hansen, S. S., \& Nichols, A. (2010). Debriefing in simulatedbased learning: Facilitating a reflective discussion. Journal of Perinatal \& Neonatal Nursing, 24(4), 302-309.

Bologna Communiqués. (1999). The bologna declaration on the european space for higher education: An explanation. Retrieved January 23, 2012, from http://ec.europa.eu/education/policies/educ/bologna/bologna.pdf

Boulet, J. (2008). Summative assessment in medicine: The promise of simulation for high-stakes evaluation. Academic Emergency Medicine, $15,1017-1024$.

Childs, J., \& Sepples, S. (2006). Clinical teaching by simulation: Lessons learned from a complex patient care case scenario. Nursing Education Perspectives, 27(3), 154-158.

Chronister, C., \& Brown, D. (in press). Comparison of simulation debriefing methods. Clinical Simulation in Nursing. doi:10.1016/j.ecns.2010. 12.005 .

Creative Research Systems. (2011). Sample size calculator. Retrieved January 23, 2012, from http://www.surveysystem.com/sscalc.htm

Decker, S., Gore, T., \& Feken, C. (2011). Simulation. In T. Bristol, \& J. Zerwehk (Eds.), Essentials of e-learning for nurse educators (pp. 277-294). Philadelphia, PA: F. A. Davis.

European Council Directives, 77/452/EEC and 77/453/EEC. (1977). Law, regulation or administrative action for nurses. Official Journal of the European Communities, 17, 8-10. Retrieved from http://eur-lex.europa. eu/LexUriServ/LexUriServ.do?uri=CELEX:31977L0453:EN:HTML

Frenk, J., Chen, L., Bhutta, Z. A., Cohen, J., Crisp, N., Evans, T., et al. (2010). Health professionals for a new century: Transforming education to strengthen health systems in an interdependent world. Lancet, 376(9756), 1923-1958. doi:10.1016/S0140-6736(10)61854-5.

Gaba, D. M. (2004). The future vision of simulation in health care. Quality and Safety in Health Care, 1, i2-i10. doi:10.1136/qshc.2004.009878.

Gauvreau, K. (2006). Hypothesis testing: Proportions. Circulation, 114(14), 1545-1548.

Gonzalez, L. (in press). Simulation workshop in Pan-America: Lessons learned. Clinical Simulation in Nursing. doi:10.1016/j.ecns.2010.08. 004.

Gravetter, F. J., \& Wallnau, L. B. (2004). Statistics for the behavioral sciences (6th ed.). Belmont, CA: Wadsworth/Thomas Learning.

Hayden, J. (2010). Use of simulation in nursing education: National survey results. Journal of Nursing Regulation, 1(3), 52-57. 
Howard, V. M., Englert, N., Kameg, K., \& Perozzi, K. (2011). Integration of simulation across the undergraduate curriculum: Student and faculty perspectives. Clinical Simulation in Nursing, 7(1), e1-e10. doi: 10.1016/j.ecns.2009.10.004.

International Nursing Association of Clinical Simulation and Learning. (2010). Mission statement. Retrieved May 30, 2011, from http://www. inacsl.org/INACSL_2010/index.php?web=y\&page=website_mission \& show_menu=yes

International Nursing Association of Clinical Simulation and Learning Board of Directors. (2011). Standards of best practice: Simulation. Clinical Simulation in Nursing, 7(4 Suppl), S1-S20, doi. org/10.1016/ j.ecns.2011.05.003. Retrieved September 30, 2011, from http://www. nursingsimulation.org/issues?issue_key=s1876-1399(11)X0005-1

Jeffries, P. R. (2007). Preface. In P. R. Jeffries (Ed.), Simulation in nursing education: From conceptualization to evaluation (pp. xi-xii). New York, NY: National League for Nursing.

Jeffries, P. R., \& McNelis, A. M. (2010). Evaluation. In W. M. Nehring, \& F. R. Lashley (Eds.), High-fidelity patient simulation in nursing education (pp. 405-424). Boston, MA: Jones and Bartlett.

Johnson-Russell, J., \& Bailey, C. (2010). Facilitating debriefing. In W. M. Nehring, \& F. R. Lashley (Eds.), High-fidelity patient simulation in nursing education (pp. 369-385). Boston, MA: Jones and Bartlett.

Leonard, B., Shuhaibar, E. L., \& Chen, R. (2010). Nursing student perceptions of intraprofessional team education using high-fidelity simulation. Journal of Nursing Education, 4(11), 628-631. doi:10.3928/0148483420100730-06.

National Council of State Boards of Nursing. (2011). National simulation study. Retrieved from https://www.ncsbn.org/2094.htm

National League for Nursing. (2010). News release June 11, 2010 : National League for Nursing task force tackling high stakes testing. Retrieved January 23, 2012, from http://www.nln.org/newsreleases/ highstakes_testing_061110.htm

Nehring, W. M. (2008). U.S. boards of nursing and the use of high-fidelity patient simulators in nursing education. Journal of Professional Nursing, 24(2), 109-117.

Nehring, W. M., \& Lashley, F. R. (2004). Current use and opinions regarding human patient simulators in nursing education: An international survey. Nursing Education Perspectives, 25(5), 244-248.
Neill, M. A., \& Wotton, K. (2011). High-fidelity simulation debriefing in nursing education: A literature review. Clinical Simulation in Nursing, 7(5), 161-168. doi:10.1016/j.ecns.2011.02.001.

Nursing and Midwifery Council-NMC Circular 36/2007. (2007). Supporting direct care through simulated practice learning in the pre-registration nursing programme. London, UK: Nursing and Midwifery Council.

Polit, D. F., \& Beck, C. T. (2008). Nursing research: Generating and assessing evidence for nursing practice (8th ed.). Philadelphia, PA: Lippincott.

Reese, C. E., Jeffries, P. R., \& Engum, S. A. (2010). Learning together: Using simulations to develop nursing and medical student collaboration. Nursing Education Perspectives, 31(1), 33-37.

Robinson, S., \& Griffiths, P. (2007). Nursing education and regulation: International profiles and perspectives. Retrieved January 23, 2012, from http://www.kcl.ac.uk/content/1/c6/03/07/33/NurseEduProfiles.pdf

Salas, E., Klein, C., King, H., Salisbury, M., Augenstein, J. S., Bimbach, D. J., et al. (2008). Debriefing medical teams: 12 evidencebased best practices and tips. Joint Commission Journal on Quality and Patient Safety, 34(9), 518-527.

Simoneau, I. L., Van Gele, P., Ledoux, I., Lavoie, S., \& Paquette, C. (2011). Reliability of the French translation of instruments designed to assess the affective learning outcomes of human patient simulation in nursing education [Abstract]. Clinical Simulation in Nursing, 7, e263-264.

Stata. (2009). Stata Statistical Software: Release 11.2. [Computer software]. College Station, TX: Stata.

Sursock, A., \& Smidt, H. (2010). Trends 2010: A decade of change in European higher education. Brussels, Belgium: European University Association.

Waxman, K. T. (2010). The development of evidence-based clinical simulation scenarios: Guidelines for nurse educators. Journal of Nursing Education, 49(1), 29-35.

Wotton, K., Davis, J., Button, D., \& Kelton, M. (2010). Third-year undergraduate nursing students' perceptions of high-fidelity simulation. Journal of Nursing Education, 49(11), 632-639, doi: 0148-4834 10.3928/0148483420100831-01.

Zabalegui, A., Macia, L., Marquez, J., Ricomá, R., Nuin, C., Mariscal, I., et al. (2006). Changes in nursing education in the European Union. Journal of Nursing Scholarship, 38(2), 114-118. 